\title{
Greek BLS Certified Providers' CPR Willingness and Skill Retention During the Pre-Vaccine Covid-19 Pandemic Period. A Survey of the Hellenic Society of Cardiology
}

\author{
George Latsios (1D ${ }^{1, *}$, Andreas Synetos' ${ }^{1, *}$, Marianna Leopoulou ${ }^{2}$, Evaggelia Stamatopoulou ${ }^{3}$, \\ Panagiotis Koukopoulos ${ }^{4}$, Charalambos Parisis ${ }^{5}$, Antonios Karanasos', Paraskevi Fragkou ${ }^{6}$, \\ Konstantinos Toutouzas', John Kanakakis ${ }^{7}$, Kostas Tsioufis (iD)
}

'First Department of Cardiology, National and Kapodistrian University of Athens, "Hippocration" General Hospital, Athens, Greece; ${ }^{2}$ Department of Cardiology, "Elpis" General Hospital, Athens, Greece; ${ }^{3}$ Catheterization Laboratory, University of Athens Medical School, "Attikon" University Hospital, Athens, Greece; ${ }^{4}$ Emergency Medical Service, Athens, Greece; ${ }^{5} 404$ General Military Hospital, Larissa, Greece; ${ }^{6}$ First Department of ICU, National and Kapodistrian University of Athens, "Evaggelismos" General Hospital, Athens, Greece; ${ }^{7}$ Department of Clinical Therapeutics, National and Kapodistrian University of Athens, "Alexandra" Hospital, Athens, Greece

*These authors contributed equally to this work

Correspondence: George Latsios, Ist Department of Cardiology, National and Kapodistrian University of Athens, Medical School, AlexAndroupoleos 9 , Athens, II527, Email glatsios@gmail.com

Objective: The aim of this study was to evaluate the level of established knowledge regarding cardiopulmonary resuscitation (CPR) during the pre-vaccine Covid-19 pandemic era of certified Basic Life Support (BLS) providers, as well as their attitude towards CPR and their willingness to provide CPR.

Methods: Certified BLS providers from courses held in Athens, Greece, were asked to complete an electronic survey regarding their knowledge of and stance towards performing CPR on victims with confirmed or suspected Covid-19 infection. Their insight on BLS courses was also assessed. Answers were collected during June 2020.

Results: Out of 5513 certified providers, $25.53 \%$ completed the survey. The majority (83.36\%) would provide CPR to a cardiac arrest victim with possible or confirmed Covid-19 infection. Regarding the use of an automated external defibrillator, most respondents anticipated that it is equally safe as in the pre-Covid-19 period (58.24\%). A more elementary level of education $(\mathrm{p}=$ 0.04) made rescuers more willing to provide CPR. Access to the European Resuscitation Council (ERC) or to the Greek National Public Health Organization (NPHO) guidelines was not correlated to the attitude towards resuscitation. Time since the last BLS seminar had no impact on the rescuers' attitude $(\mathrm{p}=0.72)$. All responders agreed that training in CPR during Covid-19 remains necessary.

Conclusion: Certified BLS providers maintained their willingness to perform CPR in cardiac arrest victims even during the prevaccine, dangerous Covid-19 pandemic period. Knowledge regarding Covid-19 CPR was satisfactory; however, continuous training, focused on the revised algorithms, was considered essential.

Keywords: BLS, covid-19, resuscitation, survey

\section{Introduction}

The evolving and expanding outbreak of the Covid-19 pandemic creates challenges regarding resuscitation efforts and requires potential modifications of established processes and protocols. With the Covid-19 incidence currently increasing exponentially worldwide, the frequency of cardiac arrests of patients with Covid-19 are also likely to increase. Under normal circumstances, cardiopulmonary resuscitation (CPR) is always provided unless a patient has a signed do-not-resuscitate order. 
CPR bares no life-threatening hazard for the providers. However, during the Covid-19 era, providers face risks related to aerosolized transmission of the SARS-CoV-2, during the CPR procedure. ${ }^{1}$

The possible risk of infection with Covid-19 of the CPR providers has led many national societies and international resuscitation councils to publish updated guidelines regarding CPR in order to assist and guide rescuers in treating victims of cardiac arrest with suspected or confirmed Covid-19.,3 These updates have also been incorporated into the curriculum of training courses for new providers and are presented as hallmarks of the new era guidelines.

Currently, the course of out-of-hospital cardiac arrest (OHCA) during Covid-19 is being defined by countries with high prevalence of the disease and overburdened health-care services. ${ }^{4-8}$ Italy experienced a $58 \%$ increase in OHCA incidence compared to 2019 but most importantly a $15 \%$ increase in mortality; $77.4 \%$ of the increase corresponds to cases directly associated with the Covid-19 infection. ${ }^{9}$ Similarly, New York had a 6-fold increase in unsuccessful OHCA $\mathrm{CPR}^{9}$ while in Paris, the percentage of patients who had an OHCA and were admitted to the hospital alive decreased from $22.8 \%$ to $12.8 \% .{ }^{10}$ These decreased rates of successful resuscitation during the pandemic period may indicate that paramedics or bystanders tend to be cautious in their resuscitation attempts, possibly due to the reluctance, in both the decision-making and the effectiveness, deriving from the fear of a possible Covid-19 infection.

The aim of this study was to evaluate the level of knowledge of Basic Life Support (BLS) providers in relation to the time elapsed from the BLS course, evaluate the changes in the attitude along with possible misconceptions regarding Covid-19-related CPR, conceptualize their attitude towards the course in the Covid-19 era and assess their willingness to provide CPR as well as their knowledge and perception on current updated protocols published by the European Resuscitation Council (ERC) and the national societies.

\section{Methods}

\section{Setting and Participants}

Certified BLS providers from 210 BLS training events held in Athens, Greece, organized by the Cardiopulmonary Resuscitation Working Group of the Hellenic Society of Cardiology (HSC) in collaboration with the ERC during the past 3 years, were asked to complete an electronic survey regarding their knowledge and behavioral changes on performing CPR in victims with confirmed or suspected Covid-19 infection. Following the outbreak of Covid-19 pandemic the participants answered a web-based survey tool containing questions regarding current knowledge, willingness to perform CPR and implementation in Clinical practice of the updated guidelines regarding resuscitation of a victim with suspected Covid-19 infection. The project was funded by the Hellenic Cardiological Society. The providers were exposed to the new protocols through their own responsibility and effort along with webinars, newsletters, and consensus documents derived mainly from the HCS. The questionnaire was sent out in late May 2020 and the answers were gathered from June $1^{\text {st }} 2020$ until June $21^{\text {st }} 2020$, during a period where anti- SARS-CoV-2 vaccines were not available.

\section{Questionnaire}

The survey was developed by the authors after several focus group sessions and was agreed on by the members of the working group of CPR of the HCS; it consisted of 18 multiple choice questions. Besides demographic information, the participants were asked about their level of education and professional status as well as their working place. Prior CPR training and the time interval from the last BLS seminar were of importance, while the rest of the questions were targeted to the Covid-19 pandemic, examining the effect of the new pandemic on their reaction when confronted with a cardiac arrest victim (proper application of all personal protection equipment (PPE), role of automated external defibrillator (AED), and significance of CPR training during the pandemic). Finally, the participants were asked whether the training is realistic and can be safely applied in practice, as well as if they were aware about the updated guidelines and associated webinars issued by the ERC and the HCS. The full questionnaire is available in the Appendix.

The goal was to establish which of the factors enquired in the questionnaire, had a favorable effect on this appropriate stance of the BLS providers. Also, it was attempted to establish if a favorable attitude could be attributed to the BLS provider having knowledge of the ERC guidelines or the local instructions (in Greece communicated by the HCS/ 
NPHO). Lastly, a connection between the actual act of CPR and the opinion of each responder towards the ERC guidelines was pursued.

Survey completion was voluntary and all participants offered their consent by liberally fulfilling the questionnaire. Furthermore, no incentive was offered. No identifying information was collected from the participants. The guidelines outlined in the Declaration of Helsinki were followed.

The study was approved by the Hellenic Cardiological Society Scientific \& Ethics Committee.

\section{Statistical Analysis}

All statistical analyses were performed by MedCalc Statistical Software version 19.1 (MedCalc Software bv, Ostend, Belgium, 2019). Categorical data are expressed as frequencies and group percentages. Possible association of the various variables (demographics, attitude towards Covid19 CPR, attitude towards CPR training) was assessed, to check if there is a relationship between answers to the various questions.

Possible correlations, regarding the factors affecting willingness to perform CPR, were assessed by means of utilizing a multiple-regression analysis, further confirmed by analysis of variance.

\section{Results}

\section{Responders' Characteristics}

Out of the 5513 certified providers, 1408 (25.53\%) answered the survey and of those 1199 participants $(78.80 \%)$ completed all survey questions. Respondents were predominantly female (67.29\%) and university-educated (56.12\%). Most of them (53.04\%) were health-care workers, the majority being nurses (34.59\%). Out of the 1021 health-care workers, $202(19.78 \%)$ were working in nursing wards, $130(12.73 \%)$ in medical offices or labs and $211(20.6 \%)$ in operating rooms, intensive care units or emergency Departments (Table 1). All had previous BLS training. Five hundred and thirty-six responders (38.48\%) had attended the BLS course 1-2 years ago and 256 participants (18.38\%) 2-3 years ago (Table 2).

\section{Attitude Towards Providing CPR}

Regarding the attitude and reaction when confronted with a cardiac arrest victim in the Covid-19 era, a total of 997 responders $(83.36 \%)$ answered that they would provide CPR to an arrest victim with possible or confirmed Covid-19 infection; 856 (71.57\%) answered that their behavior would be rather neutral, without changing anything on their response compared to their training and $141(11.79 \%)$ that they would be even more confident to provide CPR (Table 2). Most of the responders $(n=662,55.35 \%)$ answered that they would immediately start and continue chest compressions without rescue breaths, without delay for the PPE, and 520 responders (43.48\%), answered that they would apply all PPE regardless of the time delay. Moreover, only 237 responders $(19.80 \%)$ thought that CPR on a person of their close environment with whom they would already be in close social contact for hours, substantially increases their chance of infection.

Regarding the use of an AED in the event of a Covid-19 related cardiac arrest, most providers $(\mathrm{n}=693,58.24 \%)$ thought that it is as safe as the use in the pre-Covid-19 period, while 390 responders (32.77\%) answered that it is safe only if the CPR providers stand at least 2 meters away during the shock, and $107(8.99 \%)$ believed that it is a clear source of transmission of dangerous airborne droplets (Table 2).

\section{Training}

The majority of the certified BLS providers that answered (94.07\%) strongly believed that BLS training during the Covid-19 pandemic is realistic and can be safely applied in practice. However, less than half of the responders (542 persons, 45.24\%) knew that the ERC issued guidelines for modifying the resuscitation process during the Covid-19 pandemic and less than onefifth (205 responders, 17.08\%) were aware of the ERC web seminar on "Practice of Resuscitation during the Covid-19 pandemic", with only $68(5.69 \%)$ having participated in the specific course. Regarding local information by official organizations, 556 responders (46.41\%) were aware that the Greek National Public Health Organization has issued official 
Table I Eligible Participants' Demographics. Provided is the Number $(\mathrm{N})$ of Responders to Each Answer and the Corresponding Percentage \% (in Parenthesis) to the Total Population of People That Answered the Specific Question

\begin{tabular}{|c|c|}
\hline & $\begin{array}{l}\text { Responders } \\
\text { (Percentage) }\end{array}$ \\
\hline \multicolumn{2}{|l|}{ Gender } \\
\hline Male & $456(32.7 \%)$ \\
\hline Female & $938(67.3 \%)$ \\
\hline \multicolumn{2}{|l|}{ Age (years) } \\
\hline$<18$ & $21(1.50 \%)$ \\
\hline $18-24$ & $327(23.36 \%)$ \\
\hline $25-34$ & $303(21.64 \%)$ \\
\hline $35-44$ & $373(26.64 \%)$ \\
\hline $45-54$ & 300 (21.43\%) \\
\hline$>55$ & 76 (5.43\%) \\
\hline \multicolumn{2}{|l|}{ Educational level } \\
\hline Elementary, high School & 469 (33.50\%) \\
\hline College & $226(16.18 \%)$ \\
\hline University & $784(56.12 \%)$ \\
\hline Master's degree & $543(24.55 \%)$ \\
\hline $\mathrm{PhD}$ degree & 60 (4.29\%) \\
\hline \multicolumn{2}{|l|}{ Profession } \\
\hline Medical doctor & $226(16.35 \%)$ \\
\hline Registered nurse & 478 (34.59\%) \\
\hline Paramedic & $29(2.10 \%)$ \\
\hline Teacher & 90 (6.5I\%) \\
\hline Police- /fire- person & $84(6.08 \%)$ \\
\hline Other & 475 (34.37\%) \\
\hline \multicolumn{2}{|l|}{$\begin{array}{l}\text { Working place } \\
\text { (for health professionals) }\end{array}$} \\
\hline ICU/CCU & 95 (9.30\%) \\
\hline Emergency Department & $66(6.46 \%)$ \\
\hline Operating room & $50(4.90 \%)$ \\
\hline Nursing ward & 202 (19.78\%) \\
\hline Private practice/ laboratory & 130 (I2.73\%) \\
\hline Pre-hospital care & $128(12.54 \%)$ \\
\hline Other & $350(34.28 \%)$ \\
\hline
\end{tabular}

instructions for CPR during the Covid-19 pandemic, in collaboration with the HCS. Accordingly, 339 participants (46.44\%) believed that the updated CPR guidelines are clear but have not been adequately communicated, while 264 responders $(36.16 \%)$ believed that extensive training is needed before applying them.

As already stated, an important finding is that the majority of the already certified BLS instructors favored further seminars, despite the nature of the SARS-CoV-2 virus and its mode of transmission in proximity. Seminars can and should be conducted as before but with complete precautions (proper instructor training) according to $56.81 \%$, while an additional $37.26 \%$ supports the course conduction only after appropriate modifications (decrease of the seminar duration; 
Table 2 Specific Attitude Factors of the Providers and Attitude Towards Training of the Providers. Given is the Number (N) of Responders to Each Answer and the Corresponding Percentage \% (in Parenthesis) to the Total Population of People That Answered the Specific Question

\begin{tabular}{|c|c|}
\hline & $\begin{array}{l}\text { Responders } \\
\text { (Percentage) }\end{array}$ \\
\hline \multicolumn{2}{|l|}{ Specific attitude factors } \\
\hline \multicolumn{2}{|l|}{$\begin{array}{l}\text { Time elapsed since last } \\
\text { certified BLS/ERC/ HCS seminar }\end{array}$} \\
\hline $\begin{array}{l}<3 \text { months } \\
3-6 \text { months } \\
6-12 \text { months } \\
1-2 \text { years } \\
2-3 \text { years } \\
>3 \text { years }\end{array}$ & $\begin{array}{l}29(2.08 \%) \\
101(7.25 \%) \\
362(25.99 \%) \\
536(38.48 \%) \\
256(18.38 \%) \\
109(7.82 \%)\end{array}$ \\
\hline \multicolumn{2}{|l|}{ How do you believe the ongoing covid-19 pandemic will affect your response when witnessing a cardiac arrest? } \\
\hline $\begin{array}{l}\text { Positive - } \\
\text { more confident } \\
\text { Neutral - } \\
\text { as always } \\
\text { Negative - } \\
\text { I do not want to risk infection }\end{array}$ & $\begin{array}{l}14 \mid(11.79 \%) \\
856(71.57 \%) \\
199(16.64 \%)\end{array}$ \\
\hline \multicolumn{2}{|l|}{ What will you do in the case of a cardiopulmonary arrest? } \\
\hline $\begin{array}{l}\text { Perform chest compressions without rescue breaths, } \\
\text { without delay for the PPE } \\
\text { Apply and use PPE } \\
\text { regardless of the time delay } \\
\text { Avoid getting involved }\end{array}$ & $\begin{array}{l}662(55.35 \%) \\
520(43.48 \%) \\
14(1.17 \%)\end{array}$ \\
\hline \multicolumn{2}{|l|}{$\begin{array}{l}\text { Do you believe that performing CPR on a person of your close circle (eg, at home, at work etc.) with whom you spend a lot of } \\
\text { time, essentially increases your chances of contacting Covid-19? }\end{array}$} \\
\hline Yes & $\begin{array}{l}237(19.80 \%) \\
960(80.20 \%)\end{array}$ \\
\hline \multicolumn{2}{|l|}{ Automated External Defibrillation (AED) use on a cardiac arrest victim during the pandemic } \\
\hline $\begin{array}{l}\text { It is as safe as in the pre-Covid-19 period } \\
\text { It is a clear transmission hob of dangerous airborne droplets } \\
\text { It is safe only if the CPR providers stands at least } 2 \text { meters away during the shock }\end{array}$ & $\begin{array}{l}663(58.24 \%) \\
107(8.99 \%) \\
390(32.77 \%)\end{array}$ \\
\hline \multicolumn{2}{|l|}{$\begin{array}{l}\text { Attitude towards } \\
\text { training }\end{array}$} \\
\hline $\begin{array}{l}\text { CPR training (basic life support - BLS) during the Covid-19 pandemic is realistic and can be safely applied in practice } \\
\text { No - } \\
\text { it is not possible to apply all precautions in a situation of crowding and physical contact } \\
\text { Yes - } \\
\text { seminars should and must take place like as before, but with all necessary precautions (correct training) } \\
\text { Yes - } \\
\text { but modifications need to be made (less time -fewer people - distance learning) }\end{array}$ & $\begin{array}{l}71(5.93 \%) \\
680(56.81 \%) \\
446(37.26 \%)\end{array}$ \\
\hline $\begin{array}{l}\text { Are you aware that the ERC has issued guidelines for modifying resuscitation process during the Covid-19 pandemic and for using } \\
\text { personal protective equipment? }\end{array}$ & \\
\hline
\end{tabular}


Table 2 (Continued).

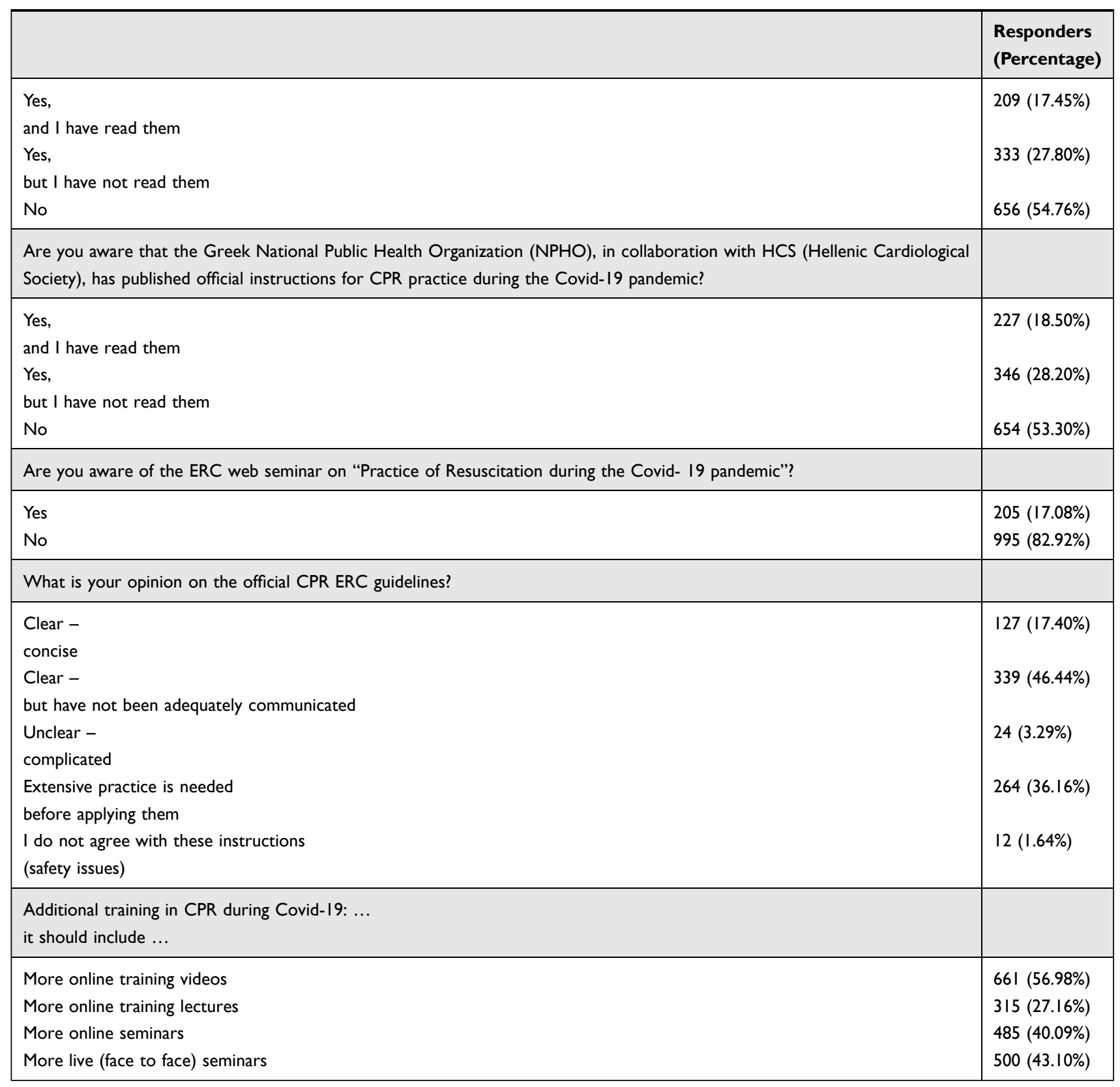

division of candidates into smaller groups; application of distal learning in feasible modules). In total, almost all (94,07\%) believed that BLS training during the Covid-19 pandemic is realistic and can be safely applied in practice, where only a minority of $5.93 \%$ ( 71 responders) do not complete precautions in crowded conditions and intense physical contact is feasible.

Finally, all agreed that additional training in CPR during Covid-19 is necessary, and it should be focused mainly on online training videos $(n=661,56.68 \%)$, more live seminars $(n=500,43.10 \%)$, more online seminars $(n=465,40.09 \%)$ and more training lectures $(\mathrm{n}=315,27.16 \%)$ (Table 2). 
Table 3 Factors Affecting Willingness of Officially Trained BLS Providers to Perform CPR During the Covid-19 Pandemic Period (ie, Question Regarding Attitude Towards CPR). Shown are the Number (N) of Providers and in Parenthesis the Proportion (in \%) of Providers to the Total Number of Providers That Answered the Specific Question and Shared the Same Attitude Towards CPR. A Positive or Even Neutral Approach Signifies That the Rescuer Would Indeed Provide CPR Despite the Possibility of an Infected with Covid-19 Cardiac Arrest Victim. A Negative Approach Signifies That the Rescuer Would Be Unwilling to Provide CPR. In the Final Column are Shown the Results of the Multiple Regression Analysis of Positive/Neutral Responders Vs Negative Responders. $R_{\text {partial }}$ is the Partial Correlation Coefficient, ie, the Coefficient of Correlation of the Variable with the Dependent Variable, Adjusted for the Effect of the Other Variables in the Model

\begin{tabular}{|c|c|c|c|c|}
\hline \multicolumn{5}{|c|}{ (A) Demographic Variables } \\
\hline Attitude Towards CPR & Positive & Neutral & Negative & $\begin{array}{c}r_{\text {partial }} \\
\text { (p-value) }\end{array}$ \\
\hline Gender & & & & $\begin{array}{c}-0.003 \\
(0.93)\end{array}$ \\
\hline Male & $53(36.55 \%)$ & $280(32.15 \%)$ & $64(31.53 \%)$ & \\
\hline Female & $92(63.45 \%)$ & 591 (7I.45\%) & $139(16.65 \%)$ & \\
\hline Age (years) & & & & $\begin{array}{c}-0.007 \\
(0.84)\end{array}$ \\
\hline Below 18 & $4(2.76 \%)$ & $10(1.14 \%)$ & $0(0.00 \%)$ & \\
\hline $18-24$ & $16(11.03 \%)$ & $220(25.14 \%)$ & $45(22.06 \%)$ & \\
\hline $25-34$ & $23(15.86 \%)$ & $201(22.97 \%)$ & 46 (22.55\%) & \\
\hline $35-44$ & $50(34.38 \%)$ & $228(26.06 \%)$ & $56(27.45 \%)$ & \\
\hline $45-54$ & $36(24.83 \%)$ & 178 (20.34\%) & $45(22.06 \%)$ & \\
\hline Above 55 & $16(11.03 \%)$ & 38 (4.34\%) & $12(5.88 \%)$ & \\
\hline Educational level & & & & $\begin{array}{l}-0.081 \\
(0.03)^{*}\end{array}$ \\
\hline Elementary, high school & 47 (32.4I\%) & 303 (34.63\%) & $54(26.47 \%)$ & \\
\hline College & $38(26.21 \%)$ & $123(14.06 \%)$ & $26(12.75 \%)$ & \\
\hline University & $58(40.00 \%)$ & $512(58.51 \%)$ & $124(60.78 \%)$ & \\
\hline Master's degree & 35 (24.14\%) & $219(25.03 \%)$ & $54(26.47 \%)$ & \\
\hline PhD degree & 9 (II.85\%) & 32 (7I.49\%) & $14(16.67 \%)$ & \\
\hline Profession & & & & $\begin{array}{c}-0.004 \\
(0.91)\end{array}$ \\
\hline Medical doctor & 13 (9.29\%) & $153(17.67 \%)$ & 32 (15.92\%) & \\
\hline Registered nurse & 55 (39.29\%) & 299 (34.53\%) & 65 (32.34\%) & \\
\hline Paramedic & 5 (3.57\%) & 17 (1.96\%) & I (0.50\%) & \\
\hline Teacher & $9(6.43 \%)$ & $53(6.12 \%)$ & 14 (6.97\%) & \\
\hline Police- / fire- person & 8 (5.7।\%) & $53(6.12 \%)$ & 18 (8.96\%) & \\
\hline Other & 0 & 0 & 0 & \\
\hline
\end{tabular}


Table 3 (Continued).

\begin{tabular}{|c|c|c|c|c|}
\hline \multicolumn{5}{|l|}{ (B) Knowledge and General attitude variables } \\
\hline Attitude Towards CPR & Positive & Neutral & Negative & $\begin{array}{c}\mathbf{r}_{\text {partial }} \\
\text { (p-value) }\end{array}$ \\
\hline $\begin{array}{l}\text { Time elapsed since } \\
\text { last certified } \\
\text { BLS/ERC seminar }\end{array}$ & & & & $\begin{array}{l}-0.013 \\
(0.72)\end{array}$ \\
\hline Less than 3 months & 5 (3.45\%) & $16(1.84 \%)$ & $2(0.98 \%)$ & \\
\hline 3-6 months & $16(11.03 \%)$ & 59 (6.78\%) & II (5.39\%) & \\
\hline $6-12$ months & $38(26.21 \%)$ & $224(25.75 \%)$ & 67 (32.84\%) & \\
\hline $\mathrm{I}-2$ years & $51(35.17 \%)$ & $34 \mathrm{I}(39.20 \%)$ & 78 (38.24\%) & \\
\hline $2-3$ years & 25 (17.24\%) & 168 (19.31\%) & 29 (14.22\%) & \\
\hline more than 3 years & $10(6.9 \%)$ & $62(7.13 \%)$ & 17 (8.33\%) & \\
\hline $\begin{array}{l}\text { CPR on a person of close circle } \\
\text { and fear of Covid-19? }\end{array}$ & & & & $\begin{array}{l}0.108 \\
(0.04)^{*}\end{array}$ \\
\hline Yes & 32 (22.22\%) & 149 (16.99\%) & 59 (29.06\%) & \\
\hline No & II 2 (77.78\%) & $728(83.01 \%)$ & 144 (70.94\%) & \\
\hline $\begin{array}{l}\text { Aware of } \\
\text { the ERC guidelines }\end{array}$ & & & & $\begin{array}{l}-0.035 \\
(0.34)\end{array}$ \\
\hline $\begin{array}{l}\text { Yes, } \\
\text { I have read them }\end{array}$ & $38(26.21 \%)$ & 148 (16.89\%) & $28(13.73 \%)$ & \\
\hline $\begin{array}{l}\text { Yes, } \\
\text { I have not read them }\end{array}$ & 49 (33.79\%) & $244(27.85 \%)$ & $50(24.5$ I\%) & \\
\hline No & $58(40.00 \%)$ & $484(55.25 \%)$ & $126(61.76 \%)$ & \\
\hline $\begin{array}{l}\text { Aware of } \\
\text { the Greek NPHO - HCS instructions for Covid 19-CPR }\end{array}$ & & & & $\begin{array}{r}-0.047 \\
(0.20)\end{array}$ \\
\hline $\begin{array}{l}\text { Yes, } \\
\text { I have read them }\end{array}$ & $34(23.61 \%)$ & 168 (19.18\%) & $25(12.32 \%)$ & \\
\hline $\begin{array}{l}\text { Yes, } \\
\text { I have not read them }\end{array}$ & $40(27.78 \%)$ & $247(28.20 \%)$ & $56(27.59 \%)$ & \\
\hline No & $70(48.61 \%)$ & $46 \mathrm{I}(52.63 \%)$ & $122(16.60 \%)$ & \\
\hline \multicolumn{5}{|l|}{$\begin{array}{l}\text { Aware of the } \\
\text { web ERC seminar } \\
\text { on Covid I9-CPR }\end{array}$} \\
\hline Yes & $32(22.07 \%)$ & $160(18.24 \%)$ & $20(9.80 \%)$ & \\
\hline No & $113(77.93 \%)$ & $717(81.76 \%)$ & $184(90.20 \%)$ & \\
\hline $\begin{array}{l}\text { Opinion on the official } \\
\text { ERC CPR guidelines }\end{array}$ & & & & $\begin{array}{c}-0.003 \\
(0.92)\end{array}$ \\
\hline $\begin{array}{l}\text { Clear - } \\
\text { concise }\end{array}$ & $25(23.58 \%)$ & 87 (16.35\%) & 17 (I5.32\%) & \\
\hline
\end{tabular}

(Continued) 
Table 3 (Continued).

(B) Knowledge and General attitude variables

\begin{tabular}{|c|c|c|c|c|}
\hline Attitude Towards CPR & Positive & Neutral & Negative & $\begin{array}{c}r_{\text {partial }} \\
\text { (p-value) }\end{array}$ \\
\hline Clear - but have not been adequately communicated & $43(40.57 \%)$ & $260(48.87 \%)$ & $48(43.24 \%)$ & \\
\hline $\begin{array}{l}\text { Unclear - } \\
\text { complicated }\end{array}$ & $2(1.89 \%)$ & $21(3.95 \%)$ & $3(2.70 \%)$ & \\
\hline Extensive practice is needed before & $41(38.68 \%)$ & $184(34.59 \%)$ & $46(4 \mid .44 \%)$ & \\
\hline $\begin{array}{l}\text { I do not agree } \\
\text { (safety issues) }\end{array}$ & I (0.94\%) & $10(1.88 \%)$ & I (0.90\%) & \\
\hline
\end{tabular}

Notes: ${ }^{*} p<0.05$, ie, the partial correlation $r_{p a r t i a l}$ is statistically significant - The variance was significant on the level of $p=0.038$, therefore the multiple correlation coefficient $r=0.157$ is statistically significant.

\section{Factors Affecting the Willingness to Perform CPR}

As aforementioned, most of the responders (83.36\%) were keen to provide CPR to a cardiac arrest victim with possible or confirmed Covid-19 infection. This is stated as a response in question (see Appendix) "Attitude towards CPR during Covid-19" with answers ranging from Positive, to Neutral, and finally to Negative. A positive or even neutral approach signifies that the rescuer would indeed provide CPR to a cardiac arrest victim even in the possibility of the victim being infected (and contagious) with Covid-19

The association between rescuers' attitude (and as a result the willingness to perform CPR) and demographics factors is shown in Table 3. In terms of demographic factors, there was no statistically significant correlation between attitude and either sex $(r=-0.003, p=0.93)$ (Figure 1) or age group $(r=-0.007, p=0.84)$.

The type of profession in general as well as each one's specific medical profession or working place had no effect on the attitude of the responder; however, the level of education influenced the certified rescuers' approach $(\mathrm{r}=-0.081, \mathrm{p}=$ 0.03 - Table 3). Interestingly, a more negative stance towards Covid-19 victims was more often seen the higher the level of education was (Figure 1).

Although the time elapsed from the certified BLS seminar had a negative impact $(r=-0.013)$ on the willingness to perform CPR on a Covid-19 victim, this failed completely to reach significance $(\mathrm{p}=0.72)$. Further to this notion, there
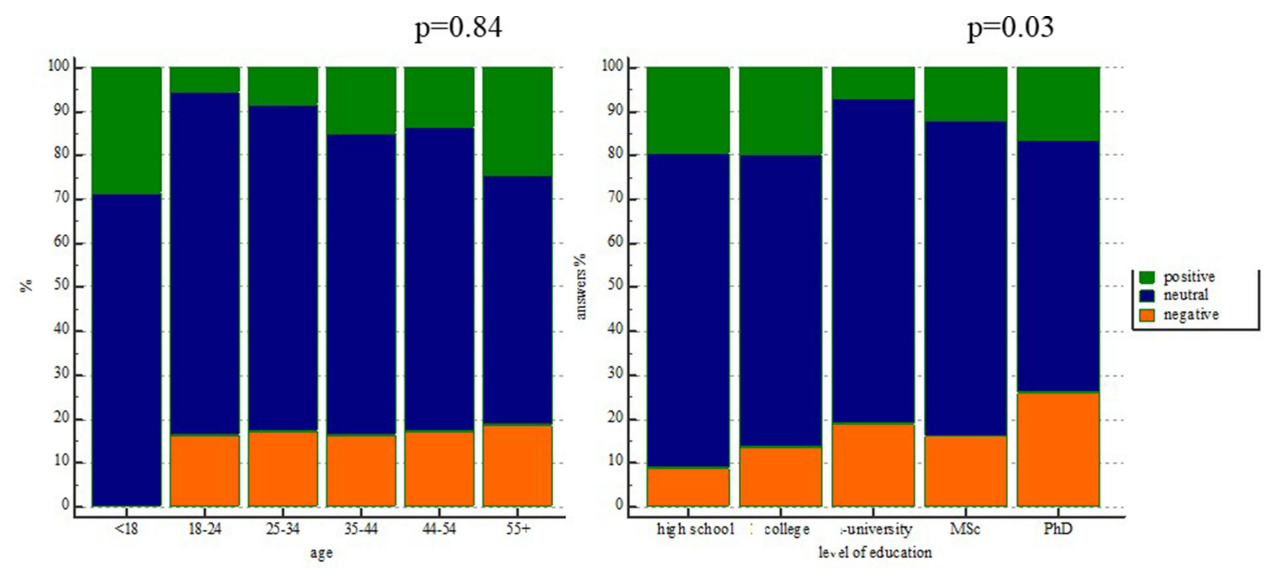

Figure I Attitude towards CPR in a Covid-19 arrested victim, according to the rescuer's age (left) and level of education (right). Positive attitude: green, Neutral attitude: blue, Negative attitude: Orange bars (100\% stacked columns). 

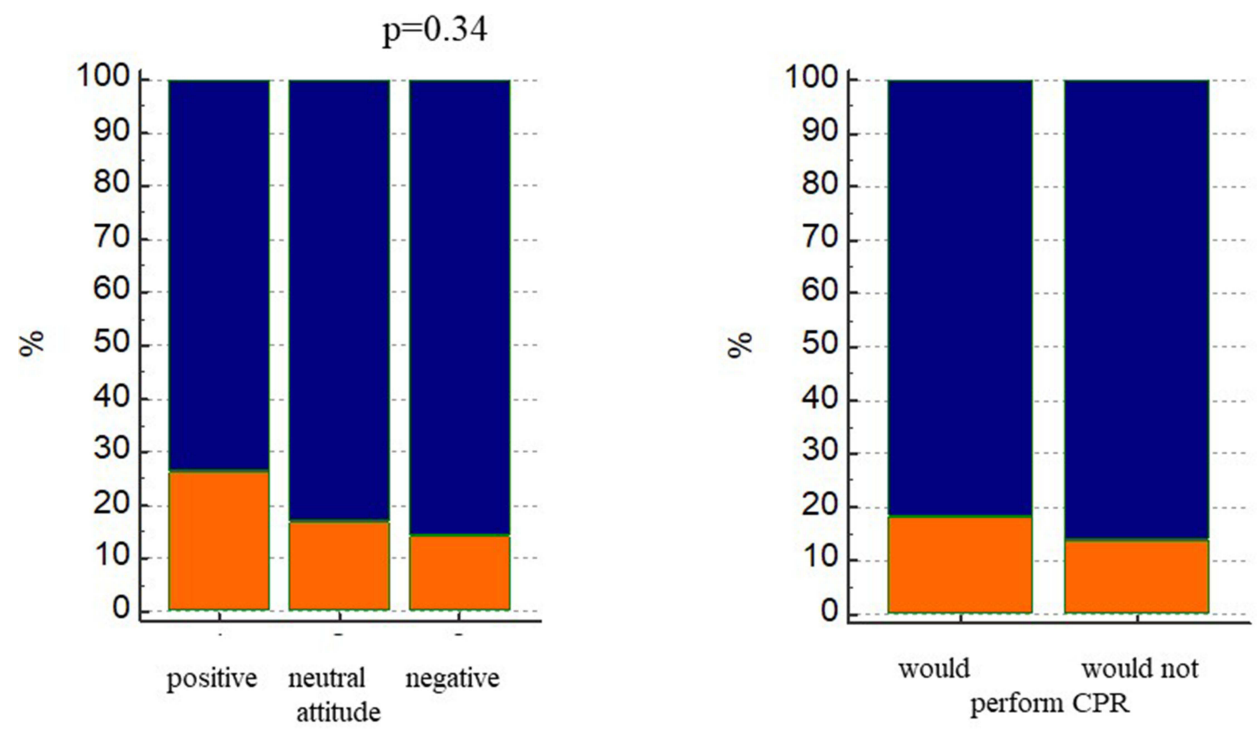

had

had not read "the ERC guidelines on covid19

Figure 2 Graphs showing the relative frequency (I00\% stacked columns) that the responders had (Orange) or had not (blue) read "the ERC guidelines regarding resuscitation in the Covid-19 period"; each bar reflects the responder's attitude towards BLS CPR. The left graph, regarding Positive/Neutral /Negative attitude towards CPR, when grouped together would eventually lead to the right graph, which showed that the provider would/ would not perform CPR (as a result of the previous question). Trained BLS providers that have read the ERC guidelines had a more positive attitude and would therefore perform CPR in suspected/ confirmed Covid-I9 victims of cardiac arrest.

was no statistically significant correlation between trained BLS providers' attitude to perform CPR and their exposure to either ERC (Figure 2) or Greek NHPO (Figure 3) guidelines ( $p=0.34$ and $p=0.20$ respectively). Interestingly, the rescuer's personal viewpoint regarding the guidelines (see details in Appendix) did not influence, in either a positive or a negative manner, his/her willingness to provide CPR.

It comes as a rather expected finding that rescuers that were positively predisposed towards performing CPR in a stranger, despite the fear of self-contamination and subsequent Covid-19 infection, stated that they would also perform CPR in a close relative $(p=0.04-$ Table 3$)$. When our study's BLS certified providers are not afraid of Covid-19 transmission from their relatives, that extends to them not being afraid to perform CPR in a stranger, even in the fear of Covid-19 infection.

\section{Discussion}

Considering the Covid-19 pandemic and the uncertainties around risk of transmission, efforts are needed, pivoting to protect CPR providers and at the same time to ensure that BLS will be provided without hesitation and delay. This twodirectional approach must be strengthened through the continuous training of BLS providers with protocols based on the updated algorithms that focus on the safety of the people involved in the CPR. We have to remember that this study's questionnaire was circulated during a time period where the unknowingness and the panic towards this viral infections reigned and the vaccines had not been made yet available.

The main and welcome finding of the study was that during the pre-vaccine Covid-19 pandemic era, most of our BLS providers were confident and willing to provide compressions-only CPR on victims of arrest, even without applying all the suggested PPE, and despite the fact that they were unaware of the ERC web seminar focused on the updated Covid19 CPR guidelines.

During the first phase of Covid-19 pandemic, ERC discouraged face-to-face, hands-on BLS teaching and mass BLS training and recommended instead individual self-directed learning, apps and Virtual Reality resources. ${ }^{11}$ This format was supposed to be very suitable for BLS education for people who wish to master BLS in cardiac arrest and for staying up to date 

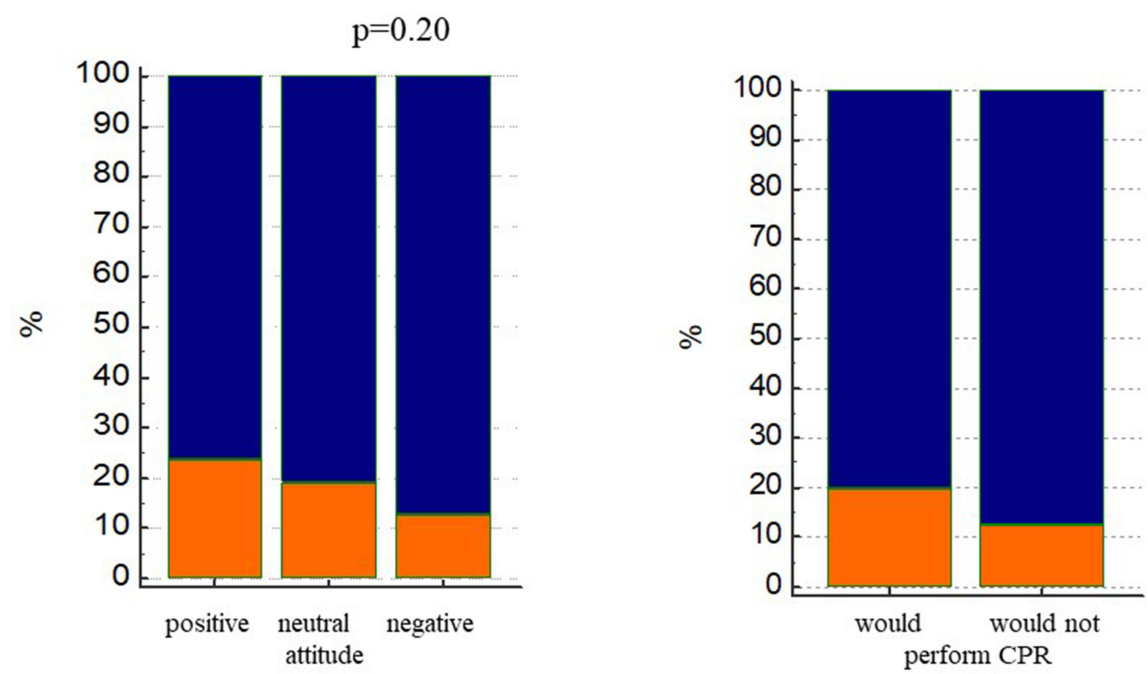

had

had not read "the Greek NPHO guidelines on covid19

Figure 3 Graphs showing the relative frequency (100\% stacked columns) that the responders had (Orange) or had not (blue) read "the Greece NPHO instructions regarding resuscitation in the Covid-19 period"; each bar reflects the responder's attitude towards BLS CPR. The left graph, regarding Positive/Neutral /Negative attitude towards CPR, when grouped together would eventually lead to the right graph, which showed that the provider would/ would not perform CPR (as a result of the previous question). Trained BLS providers that were aware of this official statement of the Greek government had a more positive attitude and would therefore perform CPR in suspected/ confirmed Covid-19 victims of cardiac arrest.

with refresher training. Although this was supposed to reduce the infection risk for both candidates and instructors, the lack of supervision endangered the whole updating process. More importantly, the already certified BLS providers were not obliged to update their knowledge and skills, as they had not been notified by any official organization or involved in an obligatory renewal online course. Most of the providers were aware of these updates, through scientific papers that had to undergo the peer-review process and then be communicated by local organizations such as the HCS or Greek National Public Health Organization. According to the results, more than half of the participants support the conduction of seminars with complete precautions (proper instructor training) while many support the course conduction only after appropriate modifications such as decrease of the seminar duration; division of candidates into smaller groups and application of distal learning in feasible modules. Notably, the ERC has subsequently addressed and applied many of these precautions in the seminar process.

According to our opinion, the most important finding of the study was the determination and willingness of BLS providers to provide CPR on arrest victims during the pandemic era; this is in concordance with previous studies. ${ }^{11}$ This shows that the mentality and the basic values of saving a life remain unaffected even in such unprecedented times, as the pandemic did not cause any decrease in the levels of willingness to provide CPR. It seems that the messages and the "good Samaritan" approach regarding resuscitation that are communicated on the official ERC BLS seminars remain constant over time, regardless if the time that has passed is 3 months or 3 years. The necessity of performing compressions-only CPR was well recognized by the responders, however the application of PPE did not get the appropriate attention. A possible explanation for this is that it has not been clarified whether the time needed for PPE application overcomes the delay in CPR initiation accompanied by the increase of no-flow time of the victim. In fact, the most important gap of knowledge is the need of covering the victim's nose and mouth with a mask or cloth, and the use of a surgical mask by the rescuers. The use of AED was well understood in most cases; however, the misconception that it is a clear source of transmission of dangerous airborne droplets and it has to be performed with the providers standing at least 2 meters away during the shock was still prevalent. Despite these discrepancies, it is encouraging that most participants required more online training or well-organized seminars.

In our study, sex or age did not affect the rescuers' attitude towards CPR. On the other hand, and quite interestingly, a more elementary level of education made rescuers more willing to provide CPR in Covid-19 suspected victims. This 
apparently contradictory finding is in contrast to previous studies in the pre-Covid-19 era. This, however, might be explained by the fact that those with more knowledge about resuscitation could be more likely to cite fear of disease of Covid-19 transmission as an obstacle to performing BLS, whereas their counterparts with less knowledge of BLS might not be aware of this possibility. ${ }^{12-14}$ Although previous studies have shown that positive attitude and willingness were significantly predicted by the recent completion of BLS training, our study failed to show such a result. ${ }^{12}$ This can be explained by the short time interval from their last BLS course as only $7.82 \%$ or the responders had their last BLS course more than 3 years from the time of the survey. Also, this is an indication of good practical and theoretical BLS skill retention in our population, as already published. ${ }^{15}$ Moreover, it should be noted that the percentages of positive attitude participants remain in higher levels compared to those in the pre-Covid-19 studies. ${ }^{13-15}$

In addition, in this study, a positive stance towards CPR in close-contact, family members was also reflected accordingly in a positive, yet cautious, rescuers' attitude regarding performing CPR in the general population during this very dangerous, pre-vaccine Covid19-pandemic period.

Historically, the possibility of contracting an infectious disease while performing CPR has been a major cause of concern. ${ }^{16}$ Similarly, during the early- and mid-2020, the spread of Covid-19 generated justified panic across the globe, as new ways to eliminate the human factor in the CPR process were examined. ${ }^{17}$ With the advent of social media related misinformation, emergency situations requiring immediate bystander interventions, such as cardiac arrest, were affected. The dangerous combination of fear and misinformation might decrease morale along with the willingness to provide help to someone who suddenly collapses in a public place and further drop the rate of bystander-initiated CPR. Although official organizations have proposed and updated their CPR guidelines, it seems that all the new measures were not adequately communicated. In our study population of 5513 BLS certified providers, less than half knew about the Covid-19 associated ERC guidelines and less than one-fifth were aware of the ERC web seminar on "Practice of Resuscitation during the Covid-19 pandemic", with even fewer having participated. This may reflect the fact that the questionnaire was issued shortly after those ERC actions. We believe that further effort, focused on multiple forms of communication and online practicing, is necessary to overcome this shortcoming.

\section{Limitations}

A possible limitation of our study is the selection bias, as only $25 \%$ of all registered certified BLS providers answered the questionnaire. Also, the study refers to people trained under specific certified official Greek organizations, with a rather great representation of health providers. Few participants underwent BLS training slightly more than 3 years ago but nevertheless were also included, since in an emergency situation as the Covid-19 pandemic, we felt that their opinion mattered. Furthermore, providers are willing to provide CPR irrespective of the time elapsed since their certification, which varies among European countries from 3 to 5 years. The study took place during the pre-vaccine Covid-19 pandemic time, where infection from SARS-CoV-2 resulted in a high likelihood of hospitalization or even death.

\section{Conclusion}

Certified BLS providers exhibit willingness and confidence to perform compressions-only CPR in unresponsive victims (family related or even unrelated) even during the Covid-19 pandemic era, an attitude that is strongly associated with a lower-level of education.

The level of knowledge regarding CPR during Covid-19 remains satisfactory; however, more training focused on the revised algorithms is essential to further increase the motivation and safety of out-of-hospital CPR.

\section{Disclosure}

The authors report no conflicts of interest in this work.

\section{References}

1. van Doremalen N, Bushmaker T, Morris DH, et al. Aerosol and surface stability of HCoV-19 (SARS-CoV-2) compared to SARS-CoV-1. medRxiv. 2020. 
2. Latsios G, Synetos A, Mastrokostopoulos A, et al. CardioPulmonary Resuscitation in patients with suspected or confirmed Covid-19. A consensus of the Working group on CardioPulmonary Resuscitation of the Hellenic Society of Cardiology. Hellenic J Cardiol. 2021;62(1):24-28. doi:10.1016/ j.hjc.2020.09.010

3. Nolan JP, Monsieurs KG, Bossaert L, et al. European Resuscitation Council COVID-19 guidelines executive summary. Resuscitation. 2020;153:45-55. doi:10.1016/j.resuscitation.2020.06.001

4. Baldi E, Sechi GM, Mare C, et al. Out-of-hospital cardiac arrest during the Covid-19 outbreak in Italy. $N$ Engl J Med. 2020;383:496-498. doi:10.1056/NEJMc2010418

5. Baldi E, Sechi GM, Mare C, et al. COVID-19 kills at home: the close relationship between the epidemic and the increase of out-of-hospital cardiac arrests. Eur Heart J. 2020;41:3045-3054. doi:10.1093/eurheartj/ehaa508

6. Lai PH, Lancet EA, Weiden MD, et al. Characteristics associated with out-of-hospital cardiac arrests and resuscitations during the novel coronavirus disease 2019 pandemic in New York City. JAMA Cardiol. 2020;19:1154.

7. Marijon E, Karam N, Jost D, et al. Out-of-hospital cardiac arrest during the COVID-19 pandemic in Paris, France: a population-based, observational study. Lancet Public Health. 2020;5:e437-e443. doi:10.1016/S2468-2667(20)30117-1

8. Paoli A, Brischigliaro L, Scquizzato T, Favaretto A, Spagna A. Out-of-hospital cardiac arrest during the COVID-19 pandemic in the Province of Padua, Northeast Italy. Resuscitation. 2020;154:47-49. doi:10.1016/j.resuscitation.2020.06.031

9. Baldi E, Sechi GM, Mare C, et al. Treatment of out-of-hospital cardiac arrest in the COVID-19 era: a 100 days experience from the Lombardy region. PLoS One. 2020;15(10):e0241028. doi:10.1371/journal.pone.0241028

10. Daily Chart. Deaths from cardiac arrests have surged in New York City. The Economist. Available from: https://www.economist.com/graphic-detail /2020/04/13/deaths-from-cardiac-arrests-havesurged-in-new-york-city. Accessed April 14, 2020.

11. Birkun A. Distant learning of BLS amid the COVID-19 pandemic: influence of the outbreak on lay trainees' willingness to attempt CPR, and the motivating effect of the training. Resuscitation. 2020;152:105-106. doi:10.1016/j.resuscitation.2020.05.023

12. Abolfotouh MA, Alnasser MA, Berhanu AN, Al-Turaif DA, Alfayez AI. Impact of basic life-support training on the attitudes of health-care workers toward cardiopulmonary resuscitation and defibrillation. BMC Health Serv Res. 2017;17:674.

13. Jelinek GA, Gennat H, Celenza T, O’Brien D, Jacobs I, Lynch D. Community attitudes towards performing cardiopulmonary resuscitation in Western Australia. Resuscitation. 2001;51:239-246. doi:10.1016/S0300-9572(01)00411-7

14. Johnston TC, Clark MJ, Dingle GA, FitzGerald G. Factors influencing Queenslanders' willingness to perform bystander cardiopulmonary resuscitation. Resuscitation. 2003;56:67-75. doi:10.1016/S0300-9572(02)00277-0

15. Latsios G, Synetos A, Leopoulou M, et al; Working Group of Cardiopulmonary Resuscitation of the Hellenic Cardiological Society. Retention of knowledge after basic training in cardiopulmonary resuscitation: a cumulative 3-year experience of certified ERC seminars of the Hellenic Society of Cardiology. Hellenic J Cardiol. 2021. doi:10.1016/j.hjc.2021.04.001

16. Fragkou P, Dimopoulou D, Latsios G, et al. Transmission of infections during cardiopulmonary resuscitation. Clin Microbiol Rev. 2021;34(4). doi:10.1128/CMR.00018-21

17. Latsios G, Leopoulou M, Synetos A, et al. The role of automated compression devices in out-of- and in- hospital cardiac arrest Can We Spare Rescuers' Hands?. Emerg Care J. 2021;17:2. doi:10.4081/ecj.2021.9525

Open Access Emergency Medicine

Dovepress

Publish your work in this journal

The Open Access Emergency Medicine is an international, peer-reviewed, open access journal publishing original research, reports, editorials, reviews and commentaries on all aspects of emergency medicine. The manuscript management system is completely online and includes a very quick and fair peer-review system, which is all easy to use. Visit http://www.dovepress.com/testimonials.php to read real quotes from published authors.

Submit your manuscript here: https://www.dovepress.com/open-access-emergency-medicine-journal 